\title{
Iodine Hall Thruster Propellant Feed System for a CubeSat
}

\author{
Kurt A. Polzin * \\ NASA-Marshall Space Flight Center, Huntsville, AL 35812
}

\begin{abstract}
I. Abstract
$\mathrm{T}$

HERE has been significant work recently in the development of iodine-fed Hall thrusters for in-space propulsion applications. ${ }^{1}$ The use of iodine as a propellant provides many advantages over present xenon-gas-fed Hall thruster systems. Iodine is a solid at ambient temperature (no pressurization required) and has no special handling requirements, making it safe for secondary flight opportunities. It has exceptionally high $\rho I_{\mathrm{sp}}$ (density times specific impulse), making it an enabling technology for small satellite near-term applications and providing system level advantages over mid-term high power electric propulsion options. Iodine provides thrust and efficiency that are comparable to xenonfed Hall thrusters while operating in the same discharge current and voltage regime, making it possible to leverage the development of flight-qualified xenon Hall thruster power processing units for the iodine application.

Work at MSFC is presently aimed at designing, integrating, and demonstrating a flight-like iodine feed system suitable for the Hall thruster application. This effort represents a significant advancement in state-of-the-art. Though Iodine thrusters have demonstrated high performance with mission enabling potential, a flight-like feed system has never been demonstrated and iodine compatible components do not yet exist. Presented in this paper is the end-to-end integrated feed system demonstration. The system includes a propellant tank with active feedback-control heating, fill and drain interfaces, latching and proportional flow control valves (PFCV), flow resistors, and flight-like CubeSat power and control electronics. Hardware is integrated into a CubeSat-sized structure, calibrated and tested under vacuum conditions, and operated under under hot-fire conditions using a Busek BHT-200 thruster designed for iodine.

Performance of the system is evaluated thorugh accurate measurement of thrust and a calibrated of mass flow rate measurement, which is a function of reservoir temperature/pressure, the flow resistors, and the setting of the PFCV. The calibration is performed using independent flow control monitoring techniques, providing an in situ measure of the flowrate as a function of controllable parameters. The reservoir temperature controls the iodine sublimation rate, providing propellant to ths thruster by pressurizing the propellant feed system to $\sim 1-2 \mathrm{psi}$. Control of the temperature and the PFCV are used to maintain reservoir pressure and keep the thruster discharge current constant.
\end{abstract}

\section{References}

${ }^{1}$ J. Szabo, B. Pote, S. Paintal, M. Robin, A. Hillier, R.D. Branam, and R.E. Huffman, "Performance Evaluation of an Iodine-Vapor Hall Thruster," J. Propuls. Power, 28(4), 848 (2012).

*Propulsion Research Engineer, Propulsion Research and Technology Applications Branch, Propulsion Systems Department. Associate Fellow AIAA. 